\title{
Comparison of Nondestructive Stress Measurement Techniques for Determination of Residual Stresses in the Heat Treated Steels
}

\author{
Hüseyin HIZLI ${ }^{1, a,{ }^{*}}$ and C. Hakan GÜR ${ }^{, 2, b}$ \\ ${ }^{1}$ Special Processes and Test Technologies Department, ROKETSAN Missiles Industries Inc., \\ Ankara, Turkey \\ ${ }^{2}$ Department of Metallurgical and Materials Engineering, Middle East Technical University, \\ Ankara, Turkey \\ ahuseyin.hizli@roketsan.com.tr, bchgur@metu.edu.tr
}

Keywords: Carburizing, Residual Stress, Magnetic Barkhausen Noise, X-Ray Diffraction, Electronic Speckle Laser Interferometry

\begin{abstract}
Service life and performance of the case-hardened machine parts are greatly dependent on the residual stress state in the surface layers which directly affects the fatigue behavior. Recently, all industrial sectors have been requested for a fast and non-destructive determination of residual stress. This study aims to monitor of the variations in surface residual stress distributions in the carburized $19 \mathrm{CrNi} 5 \mathrm{H}$ steels by means of non-destructive and semidestructive measurement techniques, Magnetic Barkhausen Noise (MBN), X-Ray Diffraction (XRD), and Electronic Speckle Pattern Interferometry (ESPI) assisted hole drilling. Microstructural investigation by optical and scanning electron microscopy, hardness measurements, and spectroscopy analysis were also conducted. To comprehend the differences in the surface residual stress state, $19 \mathrm{CrNi} 5 \mathrm{H}$ steel samples were carburized at $900^{\circ} \mathrm{C}$ for 8,10 and 13 hours, and then, tempered in the range of $180^{\circ} \mathrm{C}$ and $600^{\circ} \mathrm{C}$. Residual stress measurements carried out by XRD and ESPI assisted hole drilling showed that the compressive residual stress state exists for the case-hardened samples throughout the case depth regions, and the magnitude of the compressive residual stress decreases as the tempering temperature increases. MBN measurements showed that the $\mathrm{BN}$ activity increases with decreasing carburization time and increasing tempering temperature. It was concluded that MBN technique could be used to measure the surface residual stress distributions with a proper calibration operation.
\end{abstract}

\section{Introduction}

Carburizing is one of the most widely employed surface hardening processes to obtain high wear resistance, fatigue strength and toughness [1,2]. Carburized steels act as a composite material that consisting of the harder surface and ductile core regions with beneficial compressive residual stress in the surface layer. The compressive residual stresses are formed by various phenomena in the carburized samples, which are the differences in the volume between the highand low-carbon zones, the temperature gradients, and the local plastic deformation during the austenite-to-martensite phase transformation.

Several residual stress measurement techniques have been developed whether they are destructive or nondestructive. Among the nondestructive stress measurement techniques, X-ray diffraction is commonly used methods for materials possessing a crystalline structure [3]. The hole-drilling method is widely accepted [4] and ruled by a standard [5]. In this method, strain formed due to the stress relaxation measurement is performed by the strain gage rosettes [6]. Optical methods dependent on laser interferometry are promising in replacing the strain gage 
hole drilling method [7]. Electronic Speckle Pattern Interferometry (ESPI) has been successfully used for several years in the measurement of the residual stresses in the components [8]. Industry has been searching for methods that are capable of measuring the residual stresses accurately, quickly and easily without damaging the material under testing. A more unconventional method, the magnetic Barkhausen noise (MBN) method, is of a particular interest since it has a potential as a nondestructive industrial tool to measure residual stress and other microstructural parameters as quick and easy as possible.

\section{Experimental Procedures}

$19 \mathrm{CrNi} 5 \mathrm{H}$ steel is generally used for the production of gears, pins, and drive axles. The chemical composition and mechanical properties are given in Table 1 . The steel rods were cut into the samples with the dimensions of $165 \times 36 \times 10 \mathrm{~mm}^{3}$. All samples were labelled in accordance with the heat treatment to be applied: the first digit indicates the heat treatment i.e., carburizing (C) whereas the second digit designates the duration of the heat treatment in hours and the third digit refers to the tempering temperature.

Table 1 Mechanical properties and chemical composition of the sample (normalized condition)

\begin{tabular}{|c|c|c|c|c|c|c|c|c|c|c|c|}
\hline \multicolumn{4}{|c|}{ Material } & \multicolumn{8}{|c|}{ 19CrNi5H / SAE 3120 / En 351 (BS 970) / 20NiCr4 } \\
\hline \multicolumn{4}{|c|}{$\begin{array}{l}\text { Young's Modulus (E) } \\
\text { Poisson's ratio (v) }\end{array}$} & \multicolumn{8}{|c|}{$\begin{array}{c}201-209 \mathrm{GPa} \\
0.27-0.29\end{array}$} \\
\hline \multicolumn{4}{|c|}{$\begin{array}{c}\text { Yield Strength (YS) } \\
\text { Ultimate Tensile Strength (UTS) } \\
\% \text { Elongation }\end{array}$} & \multicolumn{8}{|c|}{$\begin{array}{l}350-550 \mathrm{MPa} \\
650-850 \mathrm{MPa} \\
\quad 8-25\end{array}$} \\
\hline \multirow{2}{*}{$\begin{array}{c}\text { Chemical Composition } \\
\text { ( } \% \text { weight) }\end{array}$} & C & Si & Mn & $\boldsymbol{P}$ & $S$ & $\mathrm{Cr}$ & $\mathrm{Ni}$ & Mo & Al & $V$ & Fe \\
\hline & 0.18 & 0.26 & 0.95 & 0.014 & 0.026 & 1.01 & 0.94 & 0.05 & 0.031 & 0.009 & balanced \\
\hline
\end{tabular}

All samples were uniformly austenitized at $880^{\circ} \mathrm{C}$ for $3 \mathrm{~h}$; then, cooled in still-air. The residual stresses induced by previous machining operations were assumed to be relieved during this treatment. The magnitude of the surface compressive residual stress varies dependent on the heat treatment parameters. Hence, various samples were prepared by applying different carburizing and tempering operations. During carburizing operations, the samples were held in the furnace using the mixture of $\mathrm{C}_{3} \mathrm{H}_{8}(\mathrm{~g})$ and the shielding gas at $900^{\circ} \mathrm{C}$ for $8 \mathrm{hrs}, 10 \mathrm{hrs}$ and $13 \mathrm{hrs}$. Upon completion of carburizing process, tempering process was applied at $180^{\circ} \mathrm{C}, 240^{\circ} \mathrm{C}$, and $600^{\circ} \mathrm{C}$ for 3 hours.

XRD stress measurements were performed using Xstress 3000 G2/G2R system and Cr-Ka radiation. Tube voltage and current were set as $30 \mathrm{kV}$ and $6.7 \mathrm{~mA}$, respectively. Prior to the measurements, the device was calibrated by stress-free iron reference sample. The peak of the ferrite $\{211\}$ plane was used for the analysis. Five tilts for both positive and negative psi angle varying from $-40^{\circ}$ to $40^{\circ}$ were used. The measurement directions for five equally distanced points on the sample surface was $0^{\circ}, 45^{\circ}, 90^{\circ}$ with respect to the rolling direction. The retained austenite content of the samples was also determined by the four-peak XRD technique.

The PRISM ESPI system was used for residual stress measurements by the ESPI assisted hole-drilling method. The drilling trials were performed on the dummy case-hardened specimens to optimize drilling parameters as such 40,000 rpm and $0.15 \mathrm{~mm} / \mathrm{sec}$. All ESPI measurements were taken along the centerline of the samples. Measurement points were $20 \mathrm{~mm}$ away from the edges of sample, and they were at least $50 \mathrm{~mm}$ apart from each other in order to avoid the effect of the deformation area used in stress calculations. Residual stresses were calculated from the deformation data, i.e. interferograms, by using the PRISMS ${ }^{\circledR}$ software which is based on the method developed by Nelson et al. and Steinzig et al. [8].

The MBN measurements were performed using commercially available equipment and its software. The measurement parameters were determined by evaluating the series of MBN signals 
obtained from all samples. In order to determine the optimum measurement parameters, the reliability, sensitivity, validity indexes of MBN signal were considered. Then, the optimized measurements parameters were determined as such that magnetizing voltage and magnetizing frequency were $10 \mathrm{~V}$ and $250 \mathrm{~Hz}$, respectively. In addition, a filter that passed frequencies from 200 to $1,000 \mathrm{kHz}$ was used. The use of such a filter range allowed the measurements to be obtained at the similar depth as the XRD and ESPI method.

For microstructural investigations, the small samples were cut, ground, polished, and etched in $2 \%$ Nital solution. The microstructures were examined by an optical microscope. Effective case depth values were determined in accordance with ISO 2639. The Vickers hardness measurements were performed at 100X magnification in accordance with ISO 6507-1.

\section{Results and Discussion}

Microstructure and Hardness. Micro hardness measurements carried out on the cross-section of the carburized and tempered samples indicated that the case region were the hardest and the hardness decreased remarkably when moved from case to core region of the samples (see Figure 1). With an increase in the duration of carburization operation, the surface hardness values rose from 783 HV1 to 835 HV1. Among the same carburization condition, an increase in the tempering temperature led the surface hardness

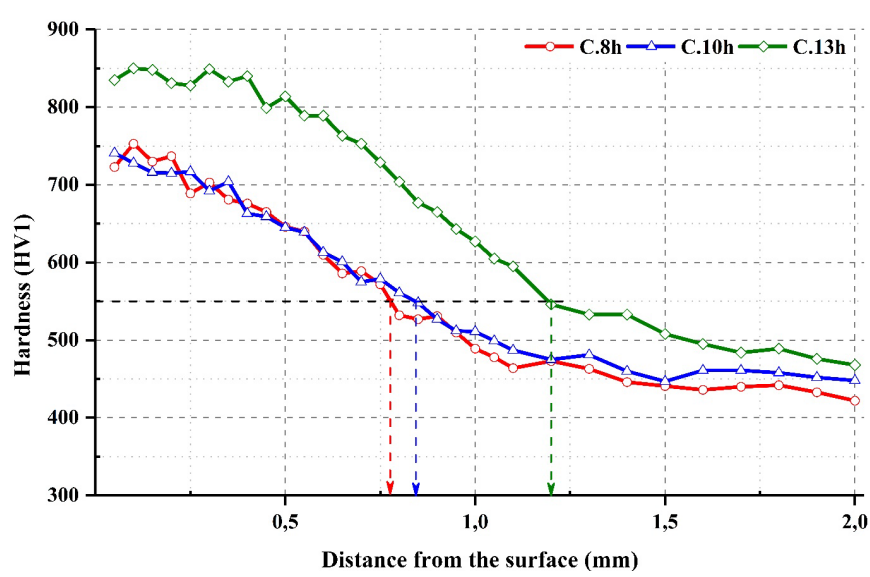

Figure 1 Effect of the carburizing time at $900^{\circ} \mathrm{C}$ on the hardness depth profile of the 19CrNi5H steel values to decrease due to the softening of martensite phase and spheroidization of the parent phase. The effective case depth of carburized samples determined as per ISO 2369 were $0.76 \mathrm{~mm}, 0.85 \mathrm{~mm}$ and $1.15 \mathrm{~mm}$ for 8hrs, 10hrs and 13hrs carburized specimens, respectively.

The micrographs seen in Figure 2 revealed that the carburized and tempered steel specimens consist of martensitic microstructure in both the core and the case regions. The needle-like shape of martensite was obtained in the quenched state, yet the application of tempering at $180^{\circ} \mathrm{C}$ led the needle-like martensite to be rounded at the tip (Figure $2 \mathrm{a}$ and $\mathrm{b}$ ). In addition, $\varepsilon$-carbide precipitation occurs in the microstructure and martensite partially loses its tetragonality at this tempering temperature. Upon increasing the tempering temperature to $240^{\circ} \mathrm{C}$, martensite continues to lose its tetragonality and the $\varepsilon$-carbide precipitations were replaced by the cementite phase (Figure 2c and d). Further increase in the tempering temperature up to $600^{\circ} \mathrm{C}$, cementite coarsens and spheroidizes seen in Figure 2e and f [2]. In addition, the X-ray diffraction technique indicated that the surface regions of the samples have retained austenite. The maximum retained austenite content was observed in the 13hrs quenched specimens as $15.4 \pm 1.9 \%$. Upon the application of tempering heat treatment, the volume percentage of the retained austenite decreased, and it was measured zero upon tempering at $240^{\circ} \mathrm{C}$ and $600^{\circ} \mathrm{C}$ since the martensite start temperature of the steel under investigation is about $190^{\circ} \mathrm{C}$.

Results of XRD Measurements. Effect of tempering on the surface residual stress distribution can be seen in Figure 3 for carburized steel samples. The compressive residual stress distributions were present on the surface of the as-quenched and tempered specimens. The magnitude of the surface residual stresses was decreased with the application of the tempering operations. When the duration of the heat treatment was increased, the magnitude of the residual stress, in the same tempered condition, was also increased. This is because the magnitude of the compressive residual stress at the surface depends on the ratio between the case and the core 
thickness. When the other factors are the same, the surface compressive residual stress will be low unless the core is thicker than the case.
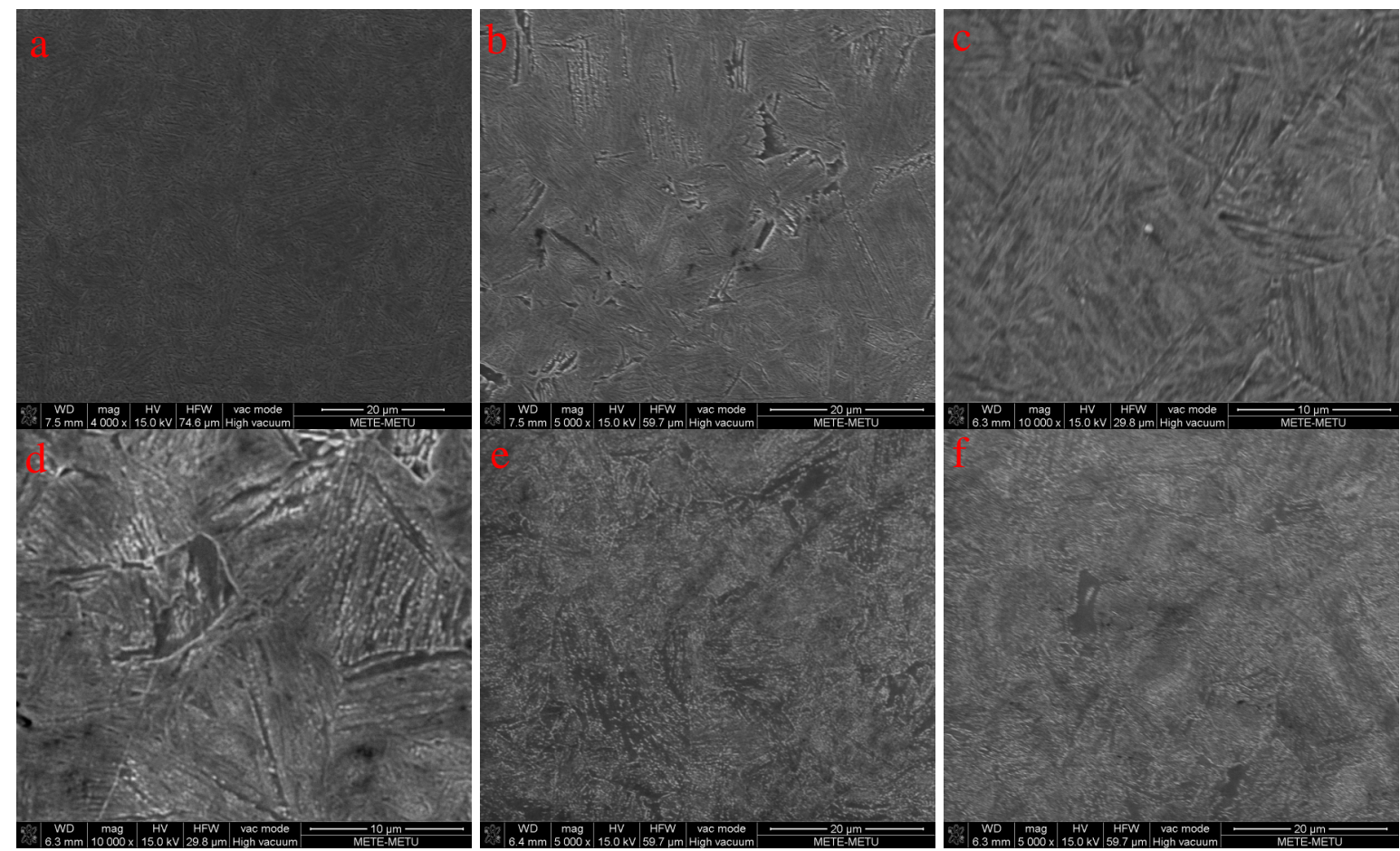

Figure 2 Representative micrographs of the carburized and tempered samples: (a) $180^{\circ} \mathrm{C}$ temper-case, (b) $180^{\circ} \mathrm{C}$ temper-core, (c) $240^{\circ} \mathrm{C}$ temper-case, (d) $240^{\circ} \mathrm{C}$ temper-core, (e) $600^{\circ} \mathrm{C}$ temper-case, and (f) $600^{\circ} \mathrm{C}$ temper-core

Results of MBN Measurements. It is well known that the MBN is affected by several microstructural features and by the stress whether applied or residual. When the magnetostriction coefficient of the material has a positive value, the MBN signal reveals an increasing trend in the direction of the applied elastic tensile stress [9]. The stress dependency of the MBN emission can be seen from Figure 4. Since the carburized and tempered steel samples having a positive magnetostriction coefficient, the

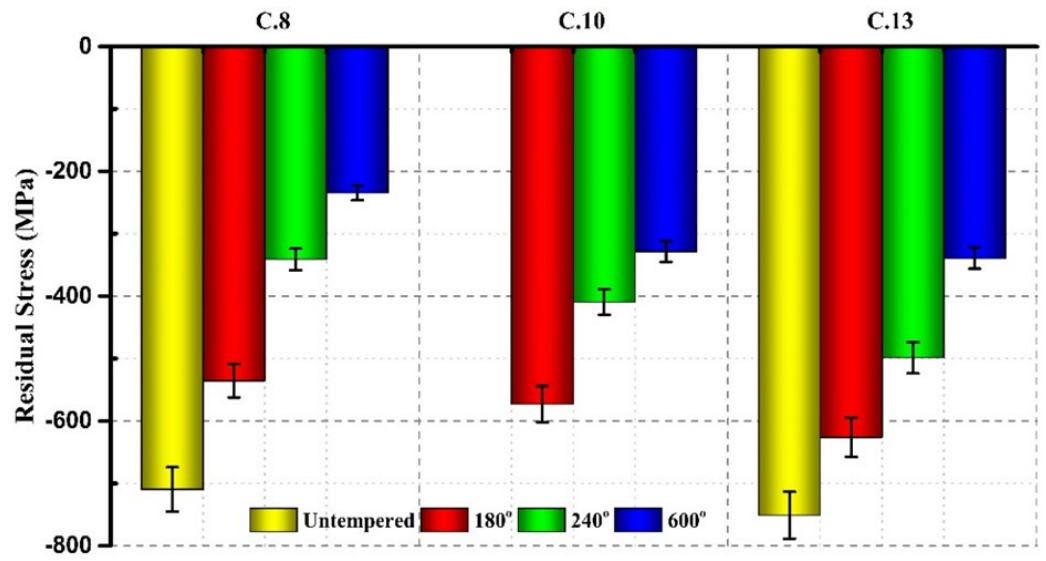

Figure 3 Effect of tempering temperature on the surface residual stress of the $19 \mathrm{CrNi5H}$ steel carburized at $900^{\circ} \mathrm{C}$ for 8 - 13 hrs (results of XRD measurements) average MBN activity decreased when the carburizing time increased, causing more negative compressive residual stress values on the surface of the sample. In addition to this, when the samples were subjected to tempering from $180^{\circ} \mathrm{C}$ to $600^{\circ} \mathrm{C}$, the average MBN activity showed increasing trend.

Results of ESPI Measurement. Fringe patterns recorded for various depth increments by 25 $\mu \mathrm{m}$ for the carburized sample are given in Figure 5. Since the single ESPI system was used, the fringe patterns acquired during the hole-drilling were generated on the horizontal plane, $\mathrm{x}$-axis, around the hole. The brighter fringes indicate the half-wavelength increments in the component 
of the measured surface displacements in the sensitivity direction. The pixels adjacent to the hole within the inner dashed circle (in $100 \mu \mathrm{m}$ depth) were excluded from the stress calculation since plastic deformation zone around the hole causes de-correlation between pre- and post-hole images [10, 11]. Tikhonov regularization was used in the ESPI system to correct the zigzag pattern of the residual stresses [5]. More than one fringe pattern were obtained and the number of the fringe images increased with increasing the depth of the hole.

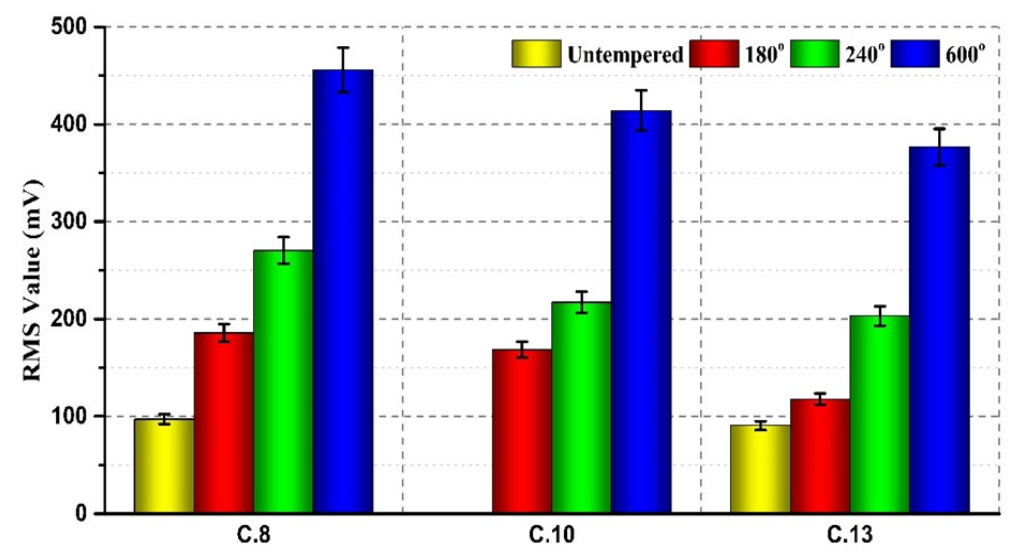

Figure 4 Effect of tempering temperature on the MBN-RMS values of the $19 \mathrm{CrNi5H}$ steel carburized at $900^{\circ} \mathrm{C}$ for 8 13hrs (the results of MBN measurements)
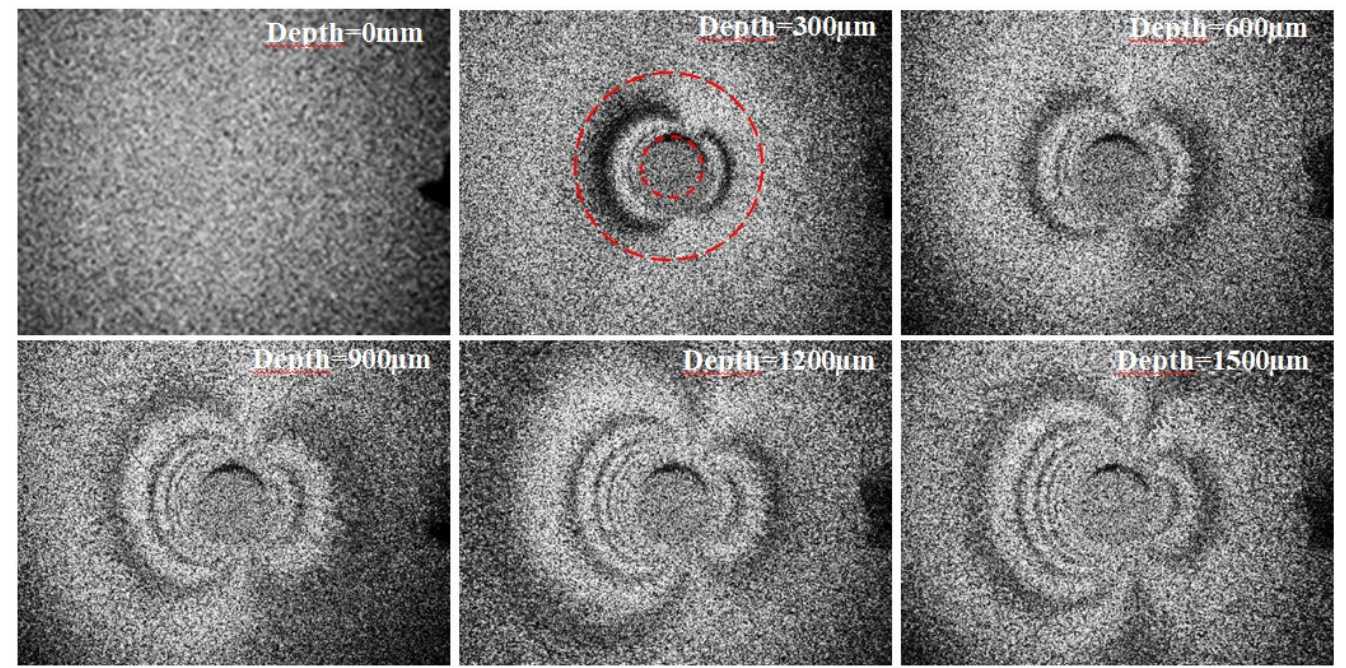

Figure 5 Fringe patterns in the carburized 19CrNi5H sample (by the ESPI method)

Surface residual stress distributions of the samples are given in Figure 6. As measured by the XRD method, the maximum compressive residual stress was observed in the 13hrs carburized sample in all tempering conditions. As observed in the other measurement techniques, the magnitude of the compressive residual stress diminished with increasing tempering temperature. Upon tempering at $600^{\circ} \mathrm{C}$, the compressive residual stress transformed to the tensile residual stress in the shallow area whereas the compressive residual stress state continued to about 1.2 $\mathrm{mm}$ beneath the surface regions of the other samples.

\section{Conclusion}

The effectiveness of three different techniques for the measurement of residual stresses in the carburized and tempered steels was investigated. Various sample sets were prepared from steel by carburizing at $900^{\circ} \mathrm{C}$ for 8 to13hrs, followed by tempering at three different temperatures. The residual stress values were determined by XRD, MBN and ESPI assisted hole drilling methods.

$\mathrm{XRD}$ stress measurements revealed that the compressive residual stress state exists on the surfaces of all samples, and its magnitudes decrease with increasing tempering temperature. The maximum compressive residual stress exists at the surface region of the as-quenched specimen while this position shifts beneath the surface after tempering. MBN measurements gave the similar tendency. The RMS value of the MBN emission increases with increasing tempering 
temperature, i.e., with decreasing magnitude of the compressive residual stress. The correlation of both techniques shows very strong positive linear relationship between the root-mean-square values of $\mathrm{MBN}$ and the measured surface residual stress values by XRD technique. Furthermore, ESPI assisted hole-drilling method is confirmed by the XRD measurements with slight differences in the magnitude of

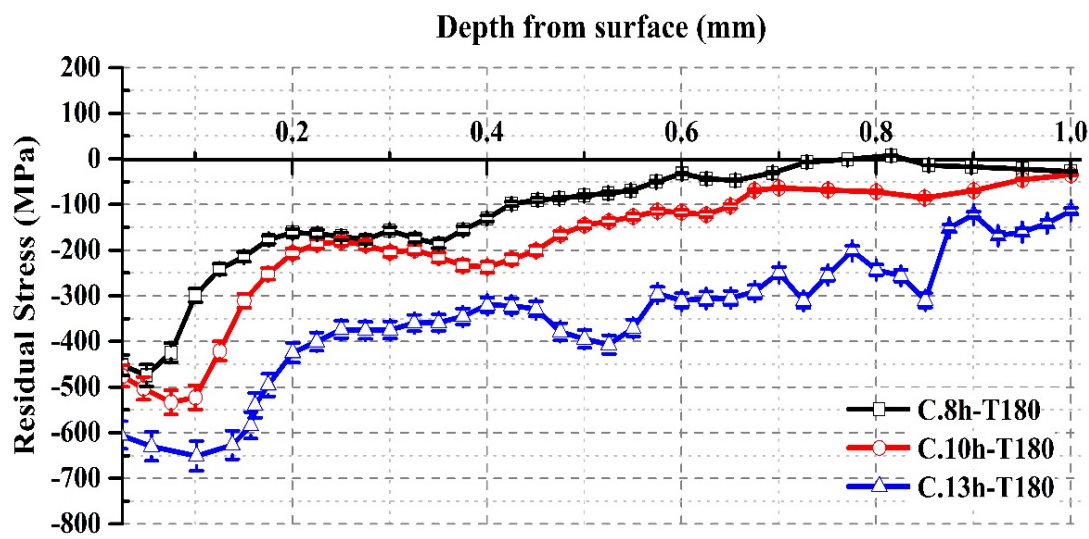

Figure 6 Effect of carburizing time on the depth profile of the residual stress in the T180 samples (by the ESPI method) the stresses till a depth of 0.8 mm. For this particular study, the ESPI assisted hole-drilling method seems to be more advantageous due to its measurement speed and practicality.

\section{References}

[1] Krauss G. (1991). Microstructures and Properties of Carburized Steels, in ASM Handbook, Vol. 4, Heat Treating, ASM International 363-375.

[2] Parrish G., (1999). Carburizing: Microstructures and Properties, Materials Park, Ohio: ASM International.

[3] Rickert, T., Thomas, J., and Suominen, L. (2014). Residual Stress Measurement of Shot-Peened Steel Rings by Barkhausen Noise, ESPI Hole-Drilling and X-Ray Diffraction. AMR, 996, 380-385.

https://doi.org/10.4028/www.scientific.net/AMR.996.380

[4] Casavola C., Campanelli L. S., and Pappalettere C. (2008). Experimental Analysis of Residual Stresses in the Selective Laser Melting Process, in Proceedings of the 11th International Congress and Exhibition on Experimental and Applied Mechanics,1479-1486.

[5] ASTM E837 (2008) Standard Test Method for Determining Residual Stresses by the Hole-Drilling Strain Gage Method, Annual Book of ASTM standards, Philadelphia: American Society for Testing and Materials, 747-753.

[6] Barile C., Casavola C., Pappalettera G., and Pappalettere C. (2013). Feasibility of Local Stress Relaxation by Laser Annealing and X-Ray Measurement. Strain, 49(5), 393-398. https://doi.org/10.1111/str.12045

[7] Albertazzi Jr. A., Peixoto Filho F., Suterio R., Amaral F. (2004) Evaluation of a Residual Stresses Measurement Device Combining a Radial In-plane ESPI and the Blind Hole Drilling Method, The International Society for Optical Engineering, Europe International Symposium Photonics.

[8] Steinzig, M. and Ponslet, E. (2003). Residual Stress Measurement Using the Hole Drilling Method and Laser Speckle Interferometry: Part I-IV. Experimental Techniques, 27 (3), 43-46.

https://doi.org/10.1111/j.1747-1567.2003.tb00114.x

[9] Gauthier, J., Krause, T., \& Atherton, D. (1998). Measurement of residual stress in steel using the magnetic Barkhausen noise technique. NDT \& E International, 31(1), 23-31.

https://doi.org/10.1016/S0963-8695(97)00023-6

[10] Furgiuele, F., Pagnotta, L., Poggialini, A. (1991). Measuring residual stresses by hole-drilling and coherent optics techniques: a numerical calibration. J. Eng. Mater. Technol. 113(1), 41.

https://doi.org/10.1115/1.2903381

[11] Barile, C., Casavola, C., Pappalettera, G., Pappalettere, C. (2014). Analysis of the effects of process parameters in residual stress measurements on titanium plates by HDM/ESPI. Measurement 48, 220-227. https://doi.org/10.1016/j.measurement.2013.11.014 